\title{
Sistema de gestión integral de propiedad, planta y equipo. Caso: Sindicato de Choferes del cantón El Guabo, Ecuador
}

Integral management system of property, plant and equipment. Case: Syndicate of Drivers of the canton El Guabo, Ecuador

\author{
María Edy Placencia Ordóñez. ${ }^{1}$, Cecilia Ivonne Narváez Zurita. ${ }^{2}$, Lesi Vanessa Giler
} Escandón. ${ }^{3}$, \& Juan Carlos Erazo Álvarez. ${ }^{4}$

DOI: $\underline{\text { https://doi.org/10.33262/visionariodigital.v3i2.1.590 }}$

\begin{abstract}
.
To have systems of integral management of fixed assets is of great relevance at present since these bines constitute the fundamental base for the development of the operations in all type of companies and even more in those that have more of a business activity and for However, in Ecuador, the majority of small and mediumsized companies do not maintain an integral conception in the management of fixed assets, so their control is deficient. In this sense, this article shows the theoretical foundation and structure of asset management under international norms and standards, as well as the proposal of a comprehensive management system of property, plant and equipment for the Cantonal Union of Professional Drivers of El Guabo, as a contribution to its strategic development.
\end{abstract}

\footnotetext{
${ }^{1}$ Universidad Católica de Cuenca, Posgradista Maestría en Contabilidad y Auditoría, Cuenca, Ecuador, meplacenciao774@psg.ucacue.edu.ec

${ }^{2}$ Universidad Católica de Cuenca, Subdirección de Posgrado, Cuenca, Ecuador, inarvaez@ucacue.edu.ec

${ }^{3}$ Universidad Católica de Cuenca, Subdirección de Posgrado, Cuenca, Ecuador, lvgilere@ucacue.edu.ec

${ }^{4}$ Universidad Católica de Cuenca, Subdirección de Posgrado, Cuenca, Ecuador, jcerazo@ucacue.edu.ec
} 
Keywords: property, plant and equipment; Integral management; Asset control.

\section{Resumen}

Disponer de sistemas de gestión integral de activos fijos es de gran relevancia en la actualidad ya que estos bienes constituyen la base fundamental para el desarrollo de las operaciones en todo tipo de empresas y más aún en aquellas que cuentan con más de una actividad empresarial y por ende una amplia diversidad de inventario, sin embargo, es preciso señalar que en el Ecuador la mayoría de pequeñas y medianas empresas no mantienen una concepción integral en la gestión de los activos fijos, por lo que su control es deficiente. En este sentido, el presente artículo muestra la fundamentación teórica y estructura de la gestión de activos bajo normas y estándares internacionales, así como la propuesta de un sistema de gestión integral de propiedad, planta y equipo para el Sindicato Cantonal de Choferes Profesionales de El Guabo, como contribución a su desarrollo estratégico.

Palabras claves: propiedad, planta y equipo; gestión integral; control de activos.

\section{Introducción.}

El sistema de gestión integral de propiedad, planta y equipo está direccionado hacia procedimientos con actividades relacionadas entre sí, con el fin de conformar procesos efectivos. Siendo para la norma Publicly Available Specification (con sus siglas PAS 55) un conjunto de acciones que trabajan coordinadamente para evitar riesgos y gastos imnecesarios durante el ciclo de vida util del bien, con el único objetivo de cumplir su propósito estratégico organizacional, asegurando una duración a mediano y largo plazo con un beneficio económico, por lo tanto, es elemental para coordinar y optimizar la complejidad de los activos tomar en cuenta los pilares detallados en la tabla 1 (BSI, 2008).

Tabla 1. Pilares fundamentales de la gestión de activos

\begin{tabular}{lll}
\hline \multicolumn{1}{c}{ Pilares } & \multicolumn{1}{c}{ Significado } \\
\hline Información de & la & $\begin{array}{l}\text { Para alcanzar los objetivos propuestos en la misión debe } \\
\text { gestión de activos }\end{array}$ \\
$\begin{array}{l}\text { plantear varias estrategias y seleccionar la más adecuada. } \\
\text { operación }\end{array}$ & $\begin{array}{l}\text { Certificar las acciones pertinentes para lograr que la estrategia } \\
\text { se cumpla con eficiencia. }\end{array}$ \\
$\begin{array}{l}\text { Variación y acciones } \\
\text { correctivas }\end{array}$ & $\begin{array}{l}\text { Controlar la validez de la estrategía para conseguir los } \\
\text { objetivos de la organización. }\end{array}$ \\
\hline
\end{tabular}

Fuente: (BSI, 2008)

Un sistema de gestión integral de activos está diseñado para soportar el plan estratégico organizacional, puesto que contien las políticas, estrategias, objetivos y planes de gestión de activos de la empresa, posibilitando con ello la integración eficaz de las actividades desarrolladas a través de los siguientes lineamientos: 
- Planificción de la política y estrategia

- Definición de los objetivos

- Elaboración de los controles y habilitadores

- Verificación de la implantación de planes de gestión de activos.

- Evaluación y mejora del desempeño, procesos a ser revisados por la gerencia.

En la actualidad, los procesos operativos de una empresa, fomentan la aplicación de herramientas integradas que van mas allá de obtener calidad productiva, ya que buscan lograr la confiabilidad en el manejo de los activos físicos, compromiso y participación de todos los actores de la organización, garantizando eficiencia y efectividad en las actividades, con apego a la norma PAS 55 al detallarse las acciones organizadas y sistematizadas ha realizar, partiendo de la evaluación de los procesos internos y críticos que no han sido considerados, definiendo estrategias que garantice el nivel óptimo de desarrollo de actividades, controlando los costos y utilizando carrectamente los activos, a fin de alcanzar un desarrollo sostenible. Ante lo expuesto, es necesario analzar los distintos modelos que tributan a logro de los objetivos estratégicos a partir de la identificación de los activos fijos como elementos escenciales para alcanzar la msión.

\section{Modelo de sustentabilidad de activos físicos}

Este modelo se fundamenta en un plan estratégico de implementación de la gestión de activos físicos dividido por etapas, ajustado a las normas PAS 55 y norma 55000 de la Organización Internacional para la Normalización (con sus siglas ISO), siendo su finalidad el mejorar la gestión de los activos en la empresa, alcanzar sustentabilidad con máximo beneficio a un mínimo costo, diagnosticar a tiempo las fallas y fortalecer la capacidad de los activos en sus distintas fases de ejecución. Para Amendola (2009) los pasos a seguir para un modelo orientados a la sustentabilidad de activos físicos debe sustentarse en lo siguiente:

1. Establecer el estado actual de la gestión de activos físicos que se lleva en la empresa frente a los verdaderos requerimientos de su administración.

2. Definir las estrategias y direccionamientos.

3. Ejecutar el plan fijando las responsabilidades del elemento humano las mismas que se ajustaran a las directrices establecidas.

4. Instaurar el plan de trabajo en la empresa, mediante los grupos responsables de la ejecución y sostenibilidad del proyecto hasta lograr procesos ajustados a las normas que regulan la actividad de manejo de activos fijos, que para el caso es la certificación del Organismo Internacional para la Estandarización (ISO),

5. Construir las estrategias necesarias para realizar los ajustes que demande el proceso y mantener un mejoramiento continuo de las acciones en la empresa para garantizar el ciclo de vida de los activos.

Modelo de aseguramiento de la capacidad de gestion de activos 
En este modelo, se considera a la gestión de activos fijos como una combinación métodos de calidad, que garantiza la capacidad para gestionar los activos mediante la implementación de cuatro principios: a) el enfoque de salida, b) las capacidades, c) aseguramiento y d) aprendizaje, constituyéndose es un grupo de procesos con gestores estratégicos y tácticos.

Por lo que, asegura la capacidad de gestión de activos, al representar la operatividad y organización de la empresa e integrar bienes y procesos a seguir con base en una estructura diseñada para cumplir un mismo objetivo organizacional, ya que debe desempeñarse como un único sistema que engloba la adquisición, registro, control y los responsables de los bienes (Amendola, 2011).

\section{Modelo de sistema de ciclo de vida del activo}

Este sistema de gestión, se fundamenta específicamente en establecer las herramientas necesarias que garanticen un mejor manejo de los activos en función de su ciclo de operatividad y de los requerimientos de la organización. Amendola (2011), indica que los costos de activos por propiedad, planta y equipo son significativos en toda empresa independiente de su actividad.

Por otra parte, es indispensable plantear lineamientos, políticas y estrategias integradas para el manejo y mantenimiento recomendable de los activos, con el fin de optimizar los recursos que maneja el personal del área operativa, para con ello, definir el ciclo de vida útil de los activos respetando siempre las normas ISO 15663. Cabe considerar que, en la práctica contable la inexactitud en el cálculo del ciclo de vida del activo genera información contable errada, repercutiendo directamente en una toma de decisiones no alineadas al costo-beneficio, siendo primordial mejorar la gestión de los activos en la empresa, alcanzar sustentabilidad con máximo beneficio y mínimo costo, diagnosticar a tiempo las fallas y fortalecer la capacidad de los activos en sus distintas fases de ejecución.

\section{El tratamiento de la propiedad, planta y equipo según las Normas Internacionales de Contabilidad (NIC)}

La NIC 16 aborda aspectos sobre el manejo contable de la propiedad, planta y equipo, detallando el tratamiento contable del inmovilizado material, que debe reflejarse en los estados financieros, de tal forma que, los usuarios de esta información conozcan los activos y el beneficio que han producido en un ciclo económico, detallando además el proceso para la contabilización, determinación del importe en libros, cargos por amortización, pérdidas y deterioro que deben ser registrados, y asi conocer la verdadera inversión en activos que posee la empresa. Según Monge (2005) la NIC 16 da las características de un elemento para ser considerado como activo de propiedad, planta y equipo, como se detalla en la figura 1. 
Figura 1. Características de propiedad, planta y equipo

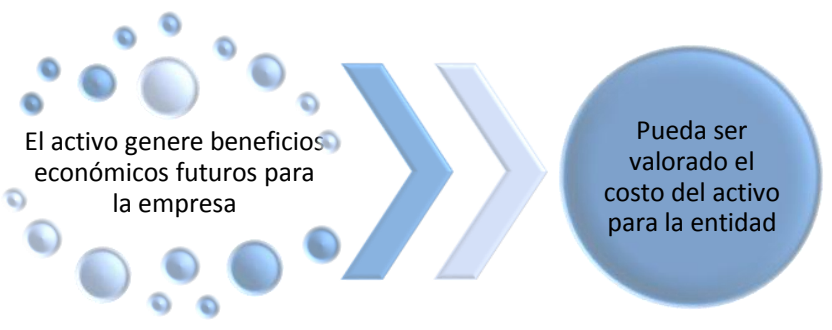

Fuente: NIC 16

A su vez Maza, Chávez y Herrera (2017) dividen a los activos en:

a) Tangibles: bienes que dan beneficios mediante su uso por más de un año, su valor residirá en los derechos de la posesión que tenga el propietario del activo, siendo grandes grupos perfectamente distribuidos, que facilitan la contabilización de datos en los registros contables, entre otros, se encuentran los equipos y maquinarias, vehículos, inmuebles, muebles y equipo de oficina, etc.

b) Intangibles: aquellos derechos que no sean identificados físicamente, pero que se espera generen beneficios futuros.

Cabe mencionar que, la NIC 16 debe ser aplicada en todos los elementos materiales movilizados, no a los activos inmovilizados que tengan tratamiento contable diferente y señalado en otra norma; para el correcto uso de la NIC 16 se requiere tener claro los términos que se requieren para el tratamiento contable, como se explica en la tabla 2:

Tabla 2. Términos para el tratamiento contable de propiedad, planta y equipo

\begin{tabular}{|c|c|}
\hline Término & Significado \\
\hline Amortizable & $\begin{array}{l}\text { Es la distribución ordenada del importe amortizable del activo en su } \\
\text { vida útil. }\end{array}$ \\
\hline Coste & Efectivo pagado al adquirir un activo. \\
\hline $\begin{array}{l}\text { Importe } \\
\text { amortizable }\end{array}$ & Es costo de activo menos valor residual. \\
\hline Importe en libros & $\begin{array}{l}\text { Valor del activo despues de realizada la deducción de la amortizacion } \\
\text { y pérdida por deterioro. }\end{array}$ \\
\hline $\begin{array}{l}\text { Importe } \\
\text { recuperable }\end{array}$ & $\begin{array}{l}\text { Valor que se obtendrá luego determinar el precio de venta neto y el } \\
\text { valor en uso del activo. }\end{array}$ \\
\hline $\begin{array}{l}\text { Inmovilizado } \\
\text { material }\end{array}$ & $\begin{array}{l}\text { Activos tangibles que poseen la empresa para propósitos } \\
\text { administrativos, arrendarlos a terceros o cuando se espera usar durante } \\
\text { más de un ejercicio económico. }\end{array}$ \\
\hline $\begin{array}{l}\text { Pérdida por } \\
\text { deterioro }\end{array}$ & Cuando la cantidad registrada en libros excede al importe recuperable. \\
\hline
\end{tabular}




\begin{tabular}{|c|c|}
\hline Término & Significado \\
\hline $\begin{array}{l}\text { Valor especifíco } \\
\text { para la entidad }\end{array}$ & $\begin{array}{l}\text { npresa tiene que recibir por el uso de un activo } \\
\text { l. }\end{array}$ \\
\hline Valor razonable & $\begin{array}{l}\text { o cancelar un pasivo, } \\
\text { ia. }\end{array}$ \\
\hline Valor & $\begin{array}{l}\text { Valor a obtener por el activo previo deducción de costos cuando } \\
\text { hubiera alcanzado la antiguiedad o término de vida útil. }\end{array}$ \\
\hline
\end{tabular}

Fuente: (IASB, 2005)

Otro aspecto a considerar, es que toda empresa independientemente de las actividades que desarrolle, requiere llevar un control exhaustivo sobre los bienes que posee, más aún si se trata de bienes que por sus características particulares representan una fuerte inversión en la organzación. El establecer mecanismos de control le permitirá al administrador verificar la existencia real de propiedad, planta y equipo, cotejar con los registros contables en el momento que se requiera, con la seguridad de que todo esté en perfecto orden, para lo cual, se requiere codificar o etiquetar los activos fijos, controlar sus entradas y salidadas, preservar en forma directa el mantenimiento de algunos bienes muebles e inmuebles, e inventariar de forma periódica la propiedad planta y equipo (Zapata, 2017).

Con base en la NIC 16, si un bien cumple con las condiciones para ser un activo fijo debe ser valorado a su costo si el pago es de contado y si este es a crédito la diferencia entre el precio de contado y el total de pagos se registrará como gastos por intereses, a menos que se capitalicen dichos intereses de acuerdo con el tratamiento alternativo permitido en la NIC 23 (costos por préstamos). Para Fierro y Fierro (2015), es necesario que el costo de los bienes de propiedades, planta y equipo contengan:

a) Valores pagados por impuesto de importación (aranceles) y otros valores indirectos (no reembosables) deduciendo valores por descuentos en el precio;

b) Costos generados hasta la ubicación y funcionamiento del bien, debiendo quedar listo para operar de la forma indicada por la gerencia; y

c) Valor calculado por desmantelamiento, es el proceso para la habilitación del lugar o sitio donde se mantuvo el bien, generandose obligaciones en las que incurre la empresa, con propósitos distintos a la producción de inventarios.

Mientras que, para la medición posterior al reconocimiento de propiedad planta y equipo es necesario establecer como política contable un modelo para el costo o revaluación, aplicados a todos los bienes que conforman el grupo de propiedad, planta y equipo.

\section{NIC 36 Deterioro del valor de los activos.}

Esta norma se aplica para contabilizar el deterioro del activo de propiedad planta y equipo, mas no para inventarios, propiedades de inversión, activos biológicos, activos surgidos por contratos de construcciones y otros activos no corrientes que posea la empresa, según se 
especifica en la NIC 5. La observación a la NIC 36 obliga al cálculo del importe recuperable de un activo asi como al reconocimiento de la pérdida por deterioro siempre que el valor en libros sea mayor al importe recuperable, este se aplicará con la finalidad de mantener un valor de provisión por deterioro que puede darse luego de haber estado el bien en uso en la empresa. La aplicación de los lineamientos de ésta norma permitirán reconocer cuando un activo puede estar deteriorado y cómo determinar el importe recuperable, aspectos importantes para ejecutar un correcto proceso contable de propiedad planta y equipo de una organización, estableciendo además, cuándo la entidad revertirá la pérdida por deterioro del valor, así como la información a revelar (Otal y Serrano, 2006).

Para estipular si un activo esta deteriorado se require revisar los datos contables, que permiten identificar si el activo en mención está contabilizado en libros a un valor superior al importe recuperable. El valor por deterioro será calculado cuando exista un indicio de la pérdida del valor del activo, una vez determinado el valor del deteriro se deberá ajustar las depreciaciones de los ejercicios contables siguientes del activo deteriorado, considerando siempre el nuevo valor contable. Se dice que un activo de propiedad planta y equipo está deteriorado cuando se encuentre dentro de los indicadores que se mencionan en la tabla 3.

Tabla 3. Indicadores que determinan deterioro de un activo

\begin{tabular}{ll}
\hline \multicolumn{1}{c}{ Indicadores internos } & \multicolumn{1}{l}{ Indicacores externos } \\
\hline Deterioro del flujo de efectivo real. & Baja del valor de las acciones. \\
$\begin{array}{l}\text { Deterioro del flujo de efectivo } \\
\text { presupuestado. }\end{array}$ & $\begin{array}{l}\text { Cambios adversos en tecnología, aspecto } \\
\text { legal y mercado. }\end{array}$ \\
$\begin{array}{l}\text { Activo obsoleto o averiado. } \\
\text { Planes de reestructuracion. }\end{array}$ & Aumento de tasas de interés. \\
$\begin{array}{l}\text { Planes de retiro del activo antes del } \\
\text { ciclo de vida. }\end{array}$ & Perdida cliente-proveedor. \\
\hline
\end{tabular}

Fuente: (IASB C. , 2001)

Por otra parte, la valoración del importe recuperable permitirá a la organización contabilizar correctamente el monto susceptible de recuperación de su propiedad planta y equipo y además conocer el valor real de la pérdida por deterioro que ha sufrido el activo, rubros que se verán reflejados en el estado de resultados indicando la real situación económica y financiera de la empresa, información que sirve de instrumento para la toma de decisiones de accionistas e inversionistas.

Para Coral (2013), el importe recuperable de un activo se obtiene entre su valor razonable menos los costos y el valor de uso. Además, la norma NIC 36 señala que no siempre se requiere determinar el valor razonable del activo, debido a que si cualquiera de los rubros excede el valor en libros, estaría frente a un activo que no ha sufrido deterioro dejando innecesario el cálculo del importe recuperable. Por lo que, es indispensable identificar 
claramente que los términos utilizados en esta norma, son valor razonable y costos y valor de usos, para no caer en errores inapropiados al momento de su aplicación, ya que al determinar el deterioro del valor del activo se conoce cuánto se va a recuperar en realidad. Concluyendo que, si los costos no han sido contabilizados bajo las observaciones de la NIC 36, ese activo no genera los beneficios esperados y los estados financieros no presentaran la realidad.

Bajo esta perspectiva, surge la necesidad de disponer de un sistema de gestión integral sobre los activos a fin de armonizar los procesos internos ajustados a los objetivos organizacionales, que será la herramienta para lograr un correcto accionar sobre los registros contables referentes a la propiedad planta y equipo. El sistema de gestión integral exige que se implementen estrategias atribuyendo responsabilidades a todos los niveles del negocio, identificando las normativas necesarias a considerar para lograr un desarrollo competitivo en el mercado, permitiendo al empresario tener una visión clara de la posición económica y financiera del negocio.

Como indica Oliver (2010) en la actualidad, existe desconocimiento por parte de las empresas en lo referente al manejo adecuado de su propiedad, planta y equipo, debido a la falta de un sistema eficiente, conllevando a no disponer valores actualizados en el estado de situación financiera; cabe indicar que estos informes son requisitos indispensables para acceder a créditos; y, así incurrir en nuevas inversiones con miras a una mayor rentabilidad para la institución.

\section{Registro y valuaciones de propiedad, planta y equipo.}

Para un adecuado registro y valuación de la propiedad, planta y equipo, se requiere inicialmente ajustar la contabildad a los tratamientos que describe la NIC 36, en donde su aplicación conlleva el tener un mejor control y una información centralizada, de tal manera que, el grupo que utiliza los estados financieros conozca la información respecto a la inversión que posee la empresa en propiedad, planta y equipo (Guevara, 2015). Considerando que es una de las mayores inversiones que se posee y a su vez que es un activo vinculado directamente con la operatividad organizacional, siendo necesario considerar su proceso de valuación.

Tal como indica la NIC 16, la valuación representa el valor razonable del activo, es decir el importe por el cual el activo puede ser intercambiado en una transacción de libre mercado. Cuando se trata de bienes tangibles y de significativa inversión tales como terrenos y edificios estos se determinarán en base al valor del mercado sujeto a las disposiciones señaladas por el International Valuation Standards Comité (IVSC), este valor del mercado puede reflejar el mayor y mejor uso del activo, es decir un uso alternativo que puede ser aprovechado, dándole a este un mayor valor. No obstante, si al contrario el activo que se pretende valuar no presenta evidencia en el mercado sobre su valor razonable, cualquiera que sea su característica, éste 
será valuado en base a los ingresos o costos de remplazo de propiedad, planta y equipo (García, 2017).

Así mismo, los bienes de difícil venta por sus particularidades en el mercado o por estar destinados específicamente a una determinada actividad que no puede ser adecuada a otra, será valuado mediante el enfoque de costo de remplazo, que generalmente son valores inferiores al valor del bien en operación. Para la valuación de propiedad, planta y equipo se debe considerar los años de uso del activo, las condiciones actuales en la que se encuentra el activo, la obsolecencia económica y funcional y el valor residual del activo al final de la vida útil.

Cabe indicar que, la valuación de propiedad, planta y equipo, debe ser realizado siempre que se observe una variación en el valor razonable (precio que se puede obtener de la venta de un bien) del activo entre un año a otro; cuando éstos valores son altamente influenciados por factores externos como en el caso de terrenos y edificios no es necesario su revaluación, pero en el caso de presentarse valores mínimos de variación del valor razonable, es suficiente la revaluación cada tres o cinco años, siendo necesario para ello considerar el precio del mercado para activos idénticos, el estado del bien y las estimaciones de sus precios, En tal razón para el tratamiento contable de estos activos se debe considerar las siguientes perspectivas:

a) Valuación de tangibles: Los valores de los activos tangibles determinados por índices, precios o tasas de depreciación no siempre reflejan el valor razonable del bien, por ello, es necesario un avalúo que permita conocer el valor real del activo. Los criterios para su valuación se establecen en la tabla 4.

Tabla 4. Criterios para valuar activos fijos tangibles

\begin{tabular}{ll}
\hline \multicolumn{1}{c}{ Activos tangibles } & Criterios de valuación \\
\hline Terrenos & Referencia en el mercado \\
Edificios locales comerciales & Referencia del mercado \\
$\begin{array}{l}\text { Centros de distribución, complejos } \\
\text { depósitos }\end{array}$ & Comparables de mercado \\
Maquinarias y equipos & Comparables en el mercados, costos nuevos o depreciados \\
Moviliarios y equipos de oficina & Comparables en el mercado, costos nuevos o depreciados \\
Vehículos & Comparables en el mercado, costos nuevos o depreciados \\
\hline
\end{tabular}

Fuente: (IASB, 2005)

b) Valuación de intangibles: Estos deben ser valuados al costo de adquisición, que es el precio de compra y los derechos de importación e impuestos y desembolsos que se pagaron en la adquisición. 


\section{Venta de propiedad, planta y equipo.}

Se requiere analizar por parte de la organización los motivos de la venta y si dicha acción generará un flujo de efectivo, en este caso es necesario determinar el monto por el cual los activos pueden ser vendidos en condiciones de mercado sumando además los gastos que la empresa realice hasta concretar la transacción. Como indica la IASB la venta de propiedad, planta y equipo se puede presentar en tres casos:

1. Venta a su valor en libros, se entenderá que un activo es vendido al precio del valor en libros sin que esto deje pérdidas o utilidades.

2. Venta a un valor superior al valor en libros contables, en esta situación se obtendrá un valor económico que se determina como utilidad, y se refleja en el balance de resultados, hasta que se dé la baja al activo, precio de costos y depreciación acumulada. Es así que la utilidad que se obtenga será la diferencia del precio de venta y el valor en libros, cuyo importe sumará a la utilidad neta del ejercicio económico obtenido en el periodo.

3. Venta a un valor menor a su valor en libros, en esta situación se esta frente a una pérdida que se refleja en el estado de resultados como una cuenta de gastos que disminuye al valor de la utilidad neta del ejercicio económico (Zapata, 2011).

\section{Metodología.}

El presente estudio fue de tipo no experimental limitándose a describir el fenómeno estudiado y a plantear una propuesta que mejore el control de los activos de la institución que es el objeto de estudio. Su enfoque fue en la mayoría de carácter cuantitativo al realizarse un tratamiento de la información proporcionada por el personal que conforma la empresa, a través de las respuestas a las encuestas aplicadas y del análisis de la información contable proporcionada. Mientras que su alcance fue descriptivo, al limitarse a presentar mediante frecuencias y porcentajes, la situación actual de la empresa.

Entre los métodos utilizados para el desarrollo de la presente investigación se puede señalar: el inductivo - deductivo, histórico - lógico y el analítico - sintético, siendo la unidad de análisis el Sindicato de Choferes Profesionales de El Guabo en la provincia de El Oro; con una población de estudio conformada por 11 personas que se desempeñan en las áreas de: contabilidad y administración, secretaria y ventas, a quienes se aplicó una encuesta estratificada, entrevista (gerente) y guía de observación (contador y auxiliar contable).

\section{Resultados.}

A través de la aplicación de los instrumentos de investigación para el análisis del control contable de propiedad, planta y equipo se obtuvieron los siguientes resultados: 


\section{- Estado de situación financiera.}

Es una representación de la situación económica de la entidad, ya que en el momento de preparar el balance general, se evidencia la liquidez o capacidad de pago de la empresa sobre obligaciones de corto y largo plazo, información relevante para la toma de decisiones administrativas en cuanto a inversiones, adquisiciones, pago anticipado de obligaciones financieras, entre otros.

En este sentido, se determinó que en el Sindicato de Choferes no cuenta con inventarios actualizados tanto física como contablemente, debido a la falta de control por parte de la administración, pues no se ha asignado un bodeguero o un encargado para los bienes, por tanto, los mismos son trasladados de un área a otra sin ningún respaldo legal.

\section{- Estado de Resultados.}

Constituye el reporte financiero más solicitado al visualizar como están oscilando las ventas, pudiéndose evidenciar todos los gastos realizados que dan lugar a la utilidad o pérdida del ejercicio en un determinado periodo, con este informe el gerente puede tomar los correctivos necesarios para obtener una mejor rentabilidad para la empresa.

En esta dimensión se analizaron los indicadores: ingresos por ventas de activos, gastos por depreciación, y gastos por pérdidas de activos. Respecto a la venta de activos fijos en función de la constatación documental efectuada, se determinó que no existe movimiento en los últimos dos años, no obstante, se pudo evidenciar en periodos anteriores que si se realiza el registro de la venta según la normativa tributaria.

Por otra parte, en los gastos por depreciación se verificó que, se realizan los ajustes necesarios el costo de los activos se ve modificado por la depreciación acumulada o el deterioro, para el cálculo del impuesto a la renta solo se considera deducibles como gasto de depreciación el porcentaje que la administración tributaria según su reglamento dispone. Según las NIIF se deben aplicar un solo método de depreciación y debe estar especificado en las políticas contables de la empresa, en el caso del Sindicato de Choferes, toma en cuenta el método de depreciación denominado línea recta.

\section{- Estado de cambios en el patrimonio.}

En este estado financiero se analiza los indicadores: utilidad en venta de activos, baja/pérdida de activos y revaluación.

En tal contexto, en la entidad, se evidenció que no se utiliza ninguno de los aspectos para la valuación de propiedad, planta y equipo, conforme lo establece la NIC 1, la cual manifiesta que los estados financieros deben reflejar la realidad de su situación financiera. Al respecto, el gerente manifiesta que es importante mantener el inventario de activos valorados, no 
obstante, no le han dado la importancia que amerita, debido en cierta medida a que gozan de una buena liquidez y no han tenido la necesidad de solicitar un crédito en una institución financiera.

\section{- Estado de flujo de efectivo.}

Este estado muestra todo el movimiento de efectivo, bancos y su equivalente como son los depósitos e inversiones, siendo parte del grupo de informes que se presentan de forma obligatoria al organismo de control, este estado es una herramienta importante para que el administrador o propietario pueda apreciar todas la entradas y salidas del efectivo y su equivalente.

Dentro de esta dimensión se analizó el disponible destinado a la adquisición de activos fijos en el Sindicato de Choferes, determinando que este proceso se realiza en base a un análisis previo a los requerimientos, considerando las políticas establecidas, clasificación y registro contable como indica la normativa, no obstante, en ciertas ocasiones la entidad se ha visto en la necesidad de postergar la compra de bienes necesarios para sus actividades debido a la falta de disponibilidad de recursos económicos.

\section{- Notas explicativas.}

En las notas iniciales, la entidad debe especificar la actividad económica, simplificar sus políticas y prácticas contables e indicar los puntos de mayor relevancia. Las notas explicativas de los estados financieros son un complemento para el análisis e interpretación de la información financiera, ya que durante su preparación hay eventos significativos en sus transacciones económicas, que deben ser revelados junto a los estados financieros para que los directivos de la empresa puedan tomar las decisiones necesarias.

En este aspecto, mediante la revisión documental se detectó que al realizar y registrar las depreciaciones de los bienes, no se detalla en notas explicativas el tipo de método de depreciación que se aplica, lo que puede conllevar a cometer errores en caso de cambio de personas responsable de esta actividad.

\section{- Políticas contables.}

Una de las políticas más importantes que se encuentran establecidas en la institución, es la oportuna entrega de la información contable, ya que con ésta información el gerente puede realizar inversiones, analizar la interacción con los proveedores, examinar las cuentas por pagar y por cobrar, elementos imprescindibles para determinar la liquidez de la empresa. 


\section{- Control y clasificación de los activos fijos.}

Es importante que los bienes estén clasificados y controlados de manera eficiente por el encargado o custodio; de una manera segura y confiable. No obstante, se pudo evidenciar que no existe un control riguroso de la propiedad, planta y equipo, siendo evidente la carencia de un proceso de codificación o etiquetado, control de entradas y salidas, mantenimiento de los bienes y los inventarios de forma periódica, en vista que al no estar totalmente controlados se vuelven vulnerables, exponiéndose a que puedan extraviarse o deteriorarse, generando en un futuro pérdidas económicas para la institución.

\section{Propuesta.}

El sistema de gestión integral de propiedad, planta y equipo propuesto para el Sindicato Cantonal de Choferes Profesionales de El Guabo, se enfoca en los procesos a ser desarrollados por los encargados y responsables del manejo de la propiedad, planta y equipo de la organización, mediante la diagramación de los flujos de procesos y el establecimiento de las política que regulan la adquisición, almacenaje y entrega al custodio del bien, permitiendo mejorar la gestión para el control y administración de sus activos. Para una mejor ejemplificación de la propuesta se presenta a continuación el esquema en la figura 2.

Figura 2. Esquema de la propuesta del sistema de gestión integral de propiedad, planta y equipo.

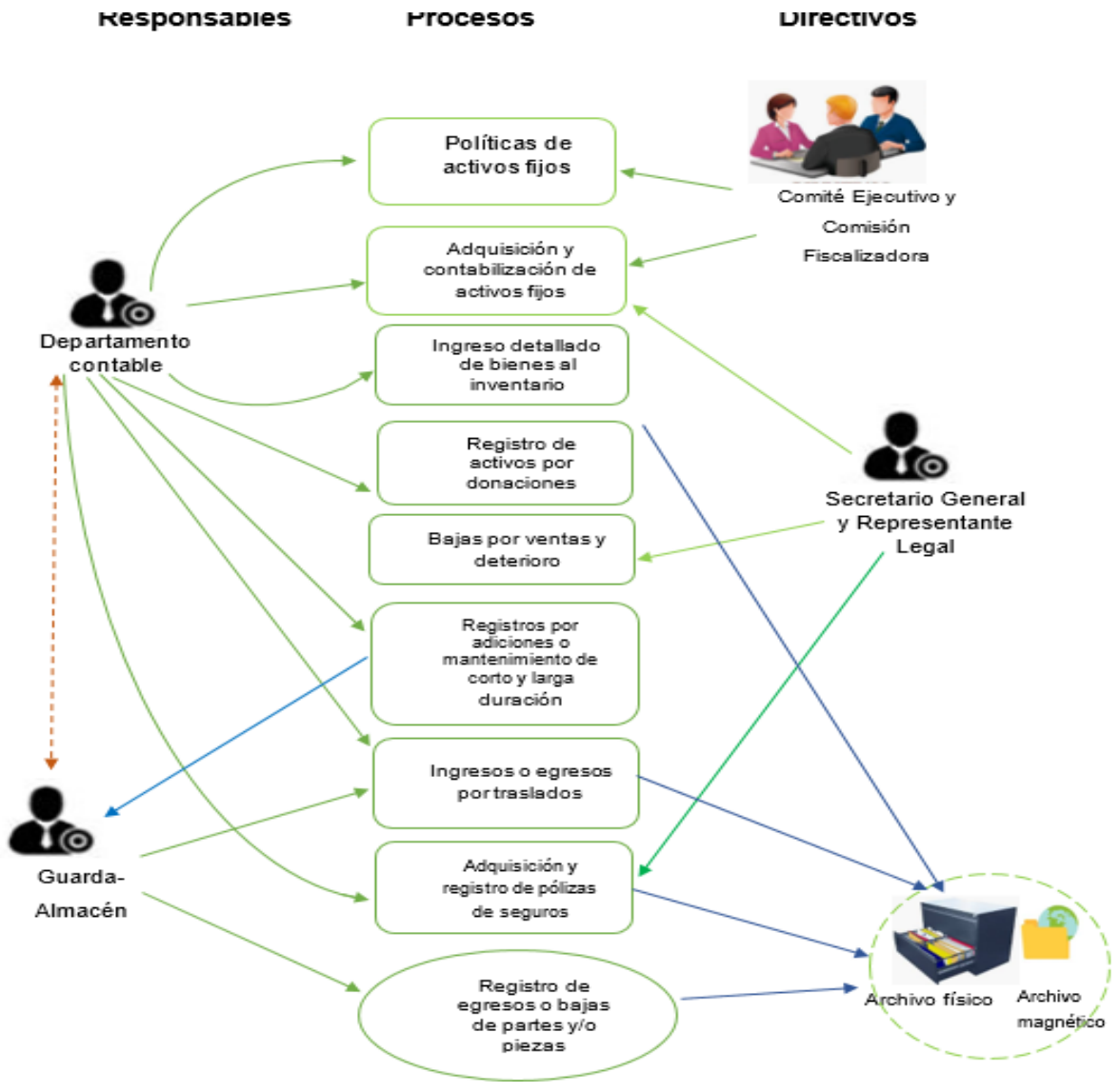




\section{Políticas para el manejo de activos fijos.}

Las políticas tienen como objetivo establecer el manejo físico de los bienes y su registro en inventarios y contabilidad, determinando los responsables o custodios dentro y fuera del sindicato, a su vez gestionar un eficiente control de los mismos, mediante un sistema que facilite el reconocimiento contable, vida útil, así como también, las modificaciones relacionadas con procesos de desmantelamiento, perdidas por deterioro, extravío, robo o mal uso. En este sentido, se han fijado políticas para cada componente.

$\checkmark$ Adquisición de bienes. - Todos los bienes que ingresen a la institución sea por compra o donación a título gratuito deben ser recibidos por el encargado o guarda-almacén, o si la naturaleza física del bien lo amerita irán directamente al departamento del empleado que lo solicitó, debiendo tener su respectivo registro contable, para que formen parte de la propiedad planta y equipo. Su adquisición se realizará considerando las siguientes políticas:

1. El departamento contable debe solicitar las cotizaciones (mínimo 2), y generar la orden de compra previa aprobación.

2. En caso de haber cambios en la petición del bien por parte del solicitante, se informará inmediatamente este, a fin de que los encargados de comprar no efectúen una adquisición incorrecta.

3. Se debe revisar la orden de compra minuciosamente, la misma que será remitida a los responsables (gerente) de su análisis y aprobación, previo a la verificación de la necesidad de la adquisición.

4. Si el monto de compra es inferior a $\$ 5,000.00$, este proceso lo ejecutará el gerente; si es de \$5,000.01 en adelante la aprobación será desarrollada por medio del comité y comisión fiscalizadora (ente controlador de los movimientos económicos). Para ello, se deberá reformar el estatuto de la empresa en el art. 22 literal e, correspondiente a las funciones del Comité ejecutivo.

5. Las órdenes de compra deben ser aprobadas por el gerente, mediante el registro de su firma al final de la orden.

6. El pago de las adquisiciones de bienes, se realizaran mediante cheque o transferencia.

7. Anualmente se debe realizar una actualización de proveedores.

8. Informar a gerencia si el bien adquirido no es de la misma característica o calidad del solicitante.

9. Todos los empleados son responsables del uso y cuidado de los bienes a ellos entregados.

10. El guarda-almacén recibe el bien por parte del proveedor con la documentación respectiva la misma que es verificada físicamente, donde debe constar lo especificado en la factura; si cumple con las especificaciones del solicitante, se realiza la clasificación, codificación del bien y registro en el kárdex de control y, en caso que no esté como indica la factura, se procede a devolver al proveedor.

11. Se realiza el acta de entrega con todas las especificaciones a nombre del responsable, 
quien a partir de la recepción del bien se encarga de su manejo y cuidado.

12. El empleado recibe el acta de entrega conjuntamente con el bien y todas sus especificaciones para proceder a verificar si está correcto de acuerdo a su solicitud presentada. Una vez verificado todo, procede a firmar el acta de entrega en señal de conformidad conjuntamente con el guarda-almacén, dejando copias de la información para su respaldo.

13. El guarda-almacén recepta la información, la misma que es archivada en la carpeta de adquisiciones de propiedad, planta y equipo.

Figura 3. Flujograma de adquisición de activos fijos

Flujograma de adquisición y contabilización de activos fijos

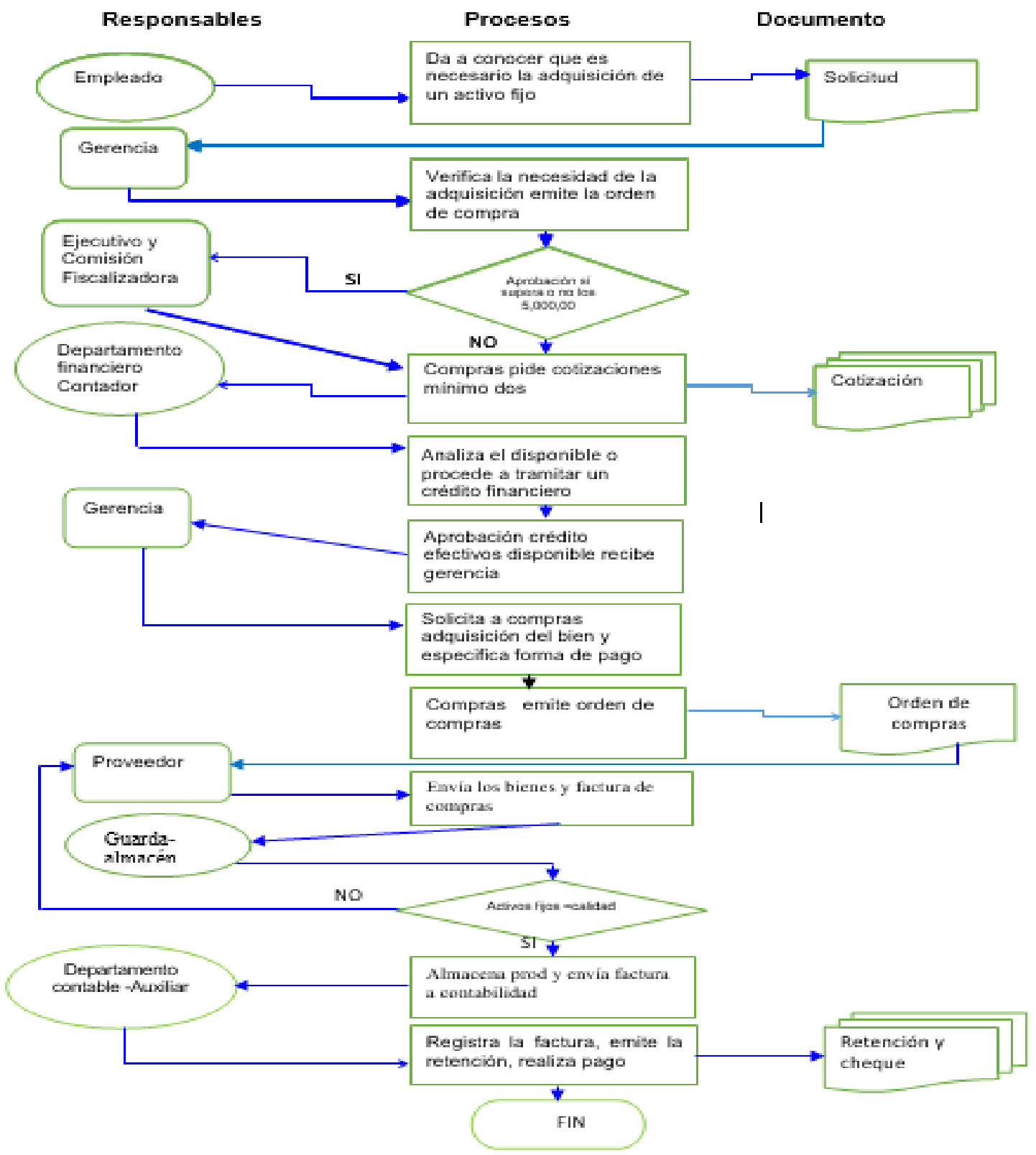


$\checkmark$ Aseguramiento de los bienes, los bienes deben estar asegurados, considerando su valor (de acuerdo a su categoría) y el riesgo a que cada uno podría estar expuesto, con el fin de salvaguardar la inversión y en un futuro no tener pérdidas económicas.

$\checkmark$ Registro contable de la propiedad, planta y equipo, el registro será llevado a cabo por el auxiliar contable o en su defecto el contador, para realizar este registro se debe verificar que esté toda la documentación que justifique la adquisición debiendo observar que, para ser catalogado como activo fijo, se debe cumplir con las siguientes características: a) ser físicamente tangible, b) que su valor sea significativo (mayor a \$500.00), c) el bien tenga una vida útil mayor a un año, d) el bien no este destinado para la venta y, e) el bien sea utilizado en la producción o comercialización de bienes o servicios.

$\checkmark$ Etiquetado o seriado de la propiedad, planta y equipo, el etiquetado es de gran importancia, puesto que de esta forma se almacena la información y todas las características de los bienes de manera detallada (lo cual quedará ingresado en el sistema y se podrá acceder al digitar o escanear el código otorgado), con el fin de que los administrativos puedan tener conocimiento de su ubicación y quienes son los responsables de los bienes (custodios) que posee la institución.

$\checkmark$ Cálculo de vida útil, para establecer la vida útil del bien, se tomará en cuenta los siguientes factores: normas de contabilidad generalmente aceptadas, Ley de Régimen Tributario Interno (art. 10 de las deducciones) y su reglamento de aplicación (art. 17 literal 6)

$\checkmark$ Baja por obsolescencia, extravío y/o robo en activos: se dará de baja un activo fijo por las siguientes causales:

- Obsolescencia, cuando haya terminado su vida útil, por disposición (decisión, modelo descontinuado, tecnología arcaica o no obtener beneficios económicos por el uso del mismo).

- Extravío, originado por confusión o perdida de una forma involuntaria por descuido del custodio.

- Robo, delito que se debe dar a conocer a las autoridades competentes, debiéndose poner la respectiva denuncia ante la fiscalía por parte del custodio o guarda-almacén, como sustento para realizar la baja de los bienes física, contablemente y ante la administración tributaria. Así mismo para recuperar el bien en caso de que las autoridades hayan localizado el mismo, es recomendable que los bienes de valores muy significativos cuenten con una póliza de seguro.

$\checkmark$ Destrucción injustificada por parte del responsable que está a cargo del manejo del bien, se aplicará una sanción o de ser necesario se dispondrá la reposición de un bien de iguales características en cuanto a calidad y precio. Al dar de baja un bien de propiedad, planta y equipo, se debe reconocer dicha pérdida en el estado de resultados del período y eliminar contablemente el bien. Se tomará en cuenta las disposiciones legales vigentes, referentes a la presentación ante el notario, con el fin de establecer la causal de baja.

$\checkmark$ Reposición de activos, este proceso se realizará con previo análisis que determine la reducción de su productividad o que ha quedado en la obsolescencia frente a otros con mejor tecnología. Esta acción debe ser solicitada en primera instancia por el custodio o 
responsable del bien en uso, estableciendo las razones para su solicitud, posteriormente el guarda-almacén será el encargado de emitir un informe al departamento contable para que éste pueda verificar si hay disponibilidad de fondos y si el valor no es significativo, el representante legal aprobará su compra, de no ser el caso en reunión de comité ejecutivo se aprueba la reposición (conforme lo establecido en cuanto al proceso de adquisición).

$\checkmark$ Control, se realizará anualmente a la totalidad de bienes que posea la institución, sin embargo, en caso que haya una pérdida o extravío se dejara una constatación física para verificar la falta del bien y con ello establecer responsabilidades y soluciones. Al finalizar la constatación de los bienes se conciliaran los datos obtenidos con la contabilidad, este control estará a cargo del departamento de contabilidad y guarda almacén.

$\checkmark$ Tratamiento de novedades de los bienes, los responsables o custodios tienen la obligación de informar todas las novedades de mayor relevancia sea por mantenimiento, mal funcionamiento de los bienes a su cargo y en el caso de bienes nuevos se verificará el tiempo que tienen de garantía, toda la información debe ser remitida a su debido tiempo al guarda-almacén siendo éste la persona responsable de gestionar ante los administrativos o sus proveedores.

$\checkmark$ Formatos, serán utilizados por el personal encargado de todos los procesos de adquisición, utilización y control, siendo una política de uso obligatorio los siguientes formatos: a) solicitud de requerimiento, b) orden de compra, d) acta de entrega recepción, e) formato de autorización para venta de propiedad, planta y equipo, f) acta de baja de propiedad, planta y equipo, g) orden de transferencia interna de propiedad, planta y equipo, h) acta de donación, i) formato para prestar un bien de propiedad, planta y equipo $y, j$ ) formato de etiquetado.

\section{Responsables del manejo de la propiedad, planta y equipo}

El establecer los responsables del manejo y custodia de la propiedad, planta y equipo de la organización, garantiza el correcto manejo de los mismos, al poder identificar quien debe precautelar el correcto manejo de los bienes que posee la empresa.

Tabla 5. Responsables del registro de ingresos de activos por donaciones

\begin{tabular}{ll}
\hline Responsable & \multicolumn{2}{c}{ Actividad - descripción } \\
\hline $\begin{array}{l}\text { Empresa donante } \\
\text { Gerente de la }\end{array}$ & $\begin{array}{l}\text { Manifiesta su interés por donar un bien, a través de un oficio. } \\
\text { empresa }\end{array}$ \\
beneficiaria & $\begin{array}{l}\text { fiscalizadora para su respectiva aceptación. } \\
\text { Si no es aceptada el oficio se archiva, cuando el oficio es aceptado }\end{array}$ \\
Dpto. contable & por el directorio se realiza el acta de aprobación. \\
Realiza el trámite correspondiente con la presentación del
\end{tabular}


formulario 108 ante el SRI se realiza la escritura pública y la

Dpto. contable registran ante el registrador de propiedad.

Registra el bien donado en contabilidad como propiedad, planta y

Dpto. contable equipo con la respectiva documentación de respaldo.

Guarda-almacén Ingreso y registro del bien por parte del responsable de los bienes de la institución.

Guarda-almacén, o quien haga sus veces deberá mantener el inventario actualizado y detallado de todos los movimientos y las novedades de los bienes de propiedad, planta y equipo, siendo esta información totalmente independiente de la información contable.

$\checkmark$ Ingreso detallado de bienes al inventario. - Este ingreso lo realiza el guarda-almacén por ser el responsable del manejo de todos los bienes según el siguiente procedimiento:

1. El guarda-almacén recibe el bien por parte del proveedor con la documentación respectiva la misma que es verificada físicamente, donde debe constar lo especificado en la factura; si cumple con las especificaciones del solicitante, se realiza la clasificación, codificación del bien y registro en el kárdex de control y, en caso que no esté como indica la factura, se procede a devolver al proveedor.

2. Se realiza el acta de entrega con todas las especificaciones a nombre del responsable, quien a partir de la recepción del bien se encarga de su manejo y cuidado.

3. El empleado recibe el acta de entrega conjuntamente con el bien y todas sus especificaciones para proceder a verificar si está correcto de acuerdo a su solicitud presentada. Una vez verificado todo, procede a firmar el acta de entrega en señal de conformidad conjuntamente con el guarda-almacén, dejando copias de la información para su respaldo.

4. El guarda-almacén recepta la información, la misma que es archivada en la carpeta de adquisiciones de propiedad, planta y equipo. 
Figura 4. Flujograma de ingreso detallado de bienes al inventario

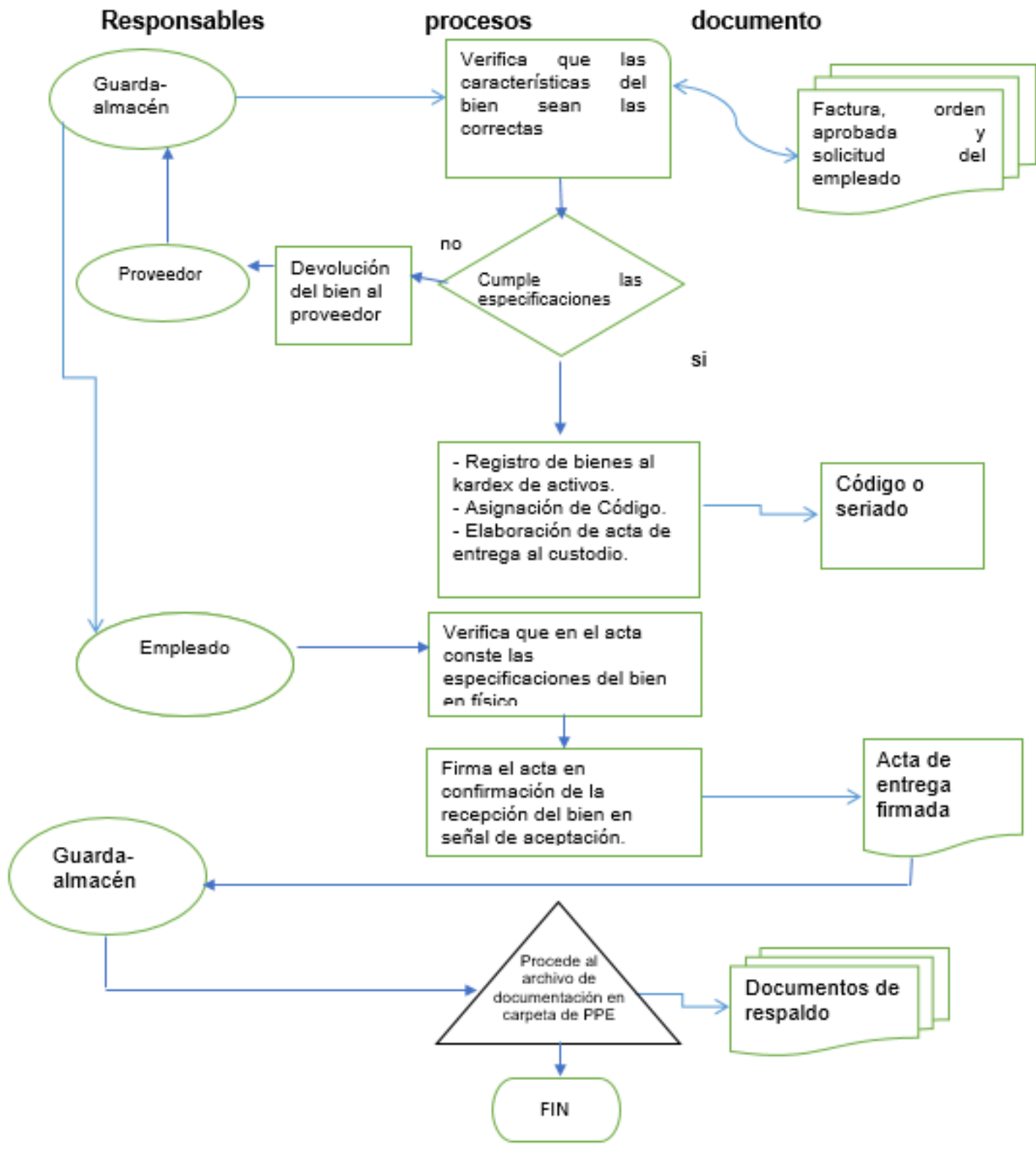

Tabla 6. Responsables del proceso de ingreso - egreso por traslado de activo fijo.

\begin{tabular}{ll}
\hline Responsable & \multicolumn{2}{c}{ Descripción } \\
\hline Bodega & $\begin{array}{l}\text { Recibe orden de requisición de salida de activo de parte de la } \\
\text { administración. }\end{array}$ \\
Bodega & $\begin{array}{l}\text { Verifica existencia del activo en bodega, de no existir se emite orden de } \\
\text { no existencia de activos al departamento de compras y administración. }\end{array}$ \\
Bodega &
\end{tabular}


Bodega

Si existe en stock selecciona los activos solicitados, emite el egreso de bodega, aplica la salida del activo descontándose la cantidad de las existencias en el sistema de inventarios de propiedad planta y equipo.

Responsable del activo

Entrega del activo al departamento solicitante, mediante acta de entrega

Bodega

Recepta activos y firma acta y envía a administración

Contabilidad

Envía copias de documentos de las transacciones de ingreso y egresos de activos a contabilidad para su registro en libros.

Recaba la documentación y registra en libros contables.

Figura 5. Flujograma de ingresos-egresos por traslados de activos fijos

Flujograma de ingreso-egreso por traslado activos fijos

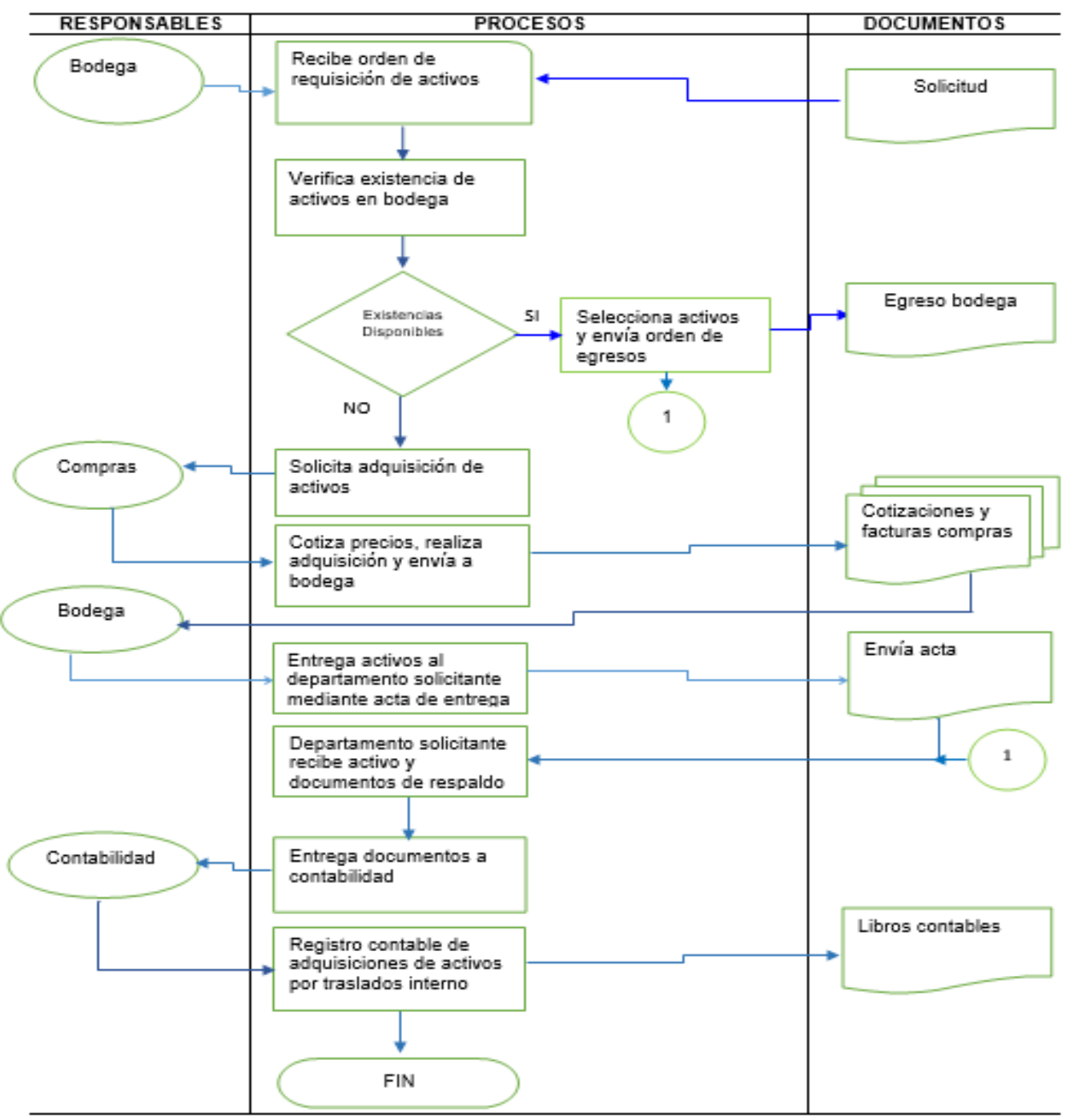


Tabla 7. Proceso de mantenimiento de corta y larga duración

\begin{tabular}{clll}
\hline Responsable & \multicolumn{3}{c}{ Actividad - Descripción } \\
\hline Administrador & Administrador programa actividades de mantenimiento de equipos. \\
Administrador & $\begin{array}{l}\text { Técnicos reciben notificación de ejecutar actividades de } \\
\text { mantenimiento de activos fijos }\end{array}$
\end{tabular}

Técnico

Técnico

Técnico procede a la ejecución de inspección y mantenimiento de activos.

Técnico

Si los activos están en buen estado se emite informe y procede a seguir en operación en el departamento que asignado.

Técnico determinación de anomalías en los activos fijos emite informe

Técnico a administración

Directorio

Solicitud de trabajo de mantenimiento del activo emitida al directorio.

Directorio

Directorio analiza trabajo de mantenimiento y aprueba o reprueba.

Técnico

Orden de reparación de activos aprobada para que sea reparado en la empresa o fuera según el requerimiento técnico.

Bodega

Técnico solicita repuestos a bodega para reparación del activo

Compras

Bodega verifica si dispone de repuestos para el mantenimiento del activo, no dispone se reporta al departamento de compras para su adquisición

Administración

Compras reporta a administración la aprobación de la adquisición.

Compras

Bodega

Administración aprueba compras de repuestos y remite informe a compras.

Técnico

Compras realiza adquisición de repuestos y envía a bodega.

Bodega recepta repuesto adjunto documento de respaldo y procede a entregar al técnico.

Técnico

Técnico recepta repuestos y ejecuta orden de trabajo de reparación y mantenimiento del activo fijo.

Contabilidad

Técnico envía reporte y documentos del costo de mantenimiento de los activos al departamento contable.

Contabilidad 


\section{Responsable Actividad - Descripción}

Contador recibe documentos y entrega al auxiliar contable para su registro.

Auxiliar contable realiza el registro del mantenimiento de activos y archiva documentación

Tabla 8. Adquisición y registros de pólizas de seguros

\begin{tabular}{ll}
\hline \multicolumn{1}{c}{ Responsabl } & \multicolumn{1}{c}{ Actividad - Descripción } \\
\hline Contabilidad & $\begin{array}{l}\text { Revisa activos fijos que requieren ser asegurados e informa a } \\
\text { administración, }\end{array}$ \\
Directivos & $\begin{array}{l}\text { Administración recibe notificación del contador y aprueba } \\
\text { contratación de póliza }\end{array}$ \\
Secretaria & Solicita cotización varias compañías de seguro \\
Contabilidad & Analiza cotización y aprueban contratación de seguro. \\
Aseguradora & $\begin{array}{l}\text { Envía comunicación a compañía de seguros detallando los bienes que } \\
\text { requieren contratar pólizas }\end{array}$ \\
Contabilidad & $\begin{array}{l}\text { Compañía de seguros firma recepción de información y envía factura } \\
\text { de contratación de póliza. }\end{array}$ \\
Contabilidad & $\begin{array}{l}\text { Contador recepta documentación del seguro de los activos verifica que } \\
\text { este correcto y entrega al auxiliar contable para su registro. }\end{array}$ \\
Archivo & $\begin{array}{l}\text { Auxiliar contable registra la factura de póliza, emite el pago y envía } \\
\text { documentos para archivo. }\end{array}$ \\
\hline $\begin{array}{l}\text { Archivo de pólizas de seguros de activos fijos departamento de } \\
\text { archivo. }\end{array}$
\end{tabular}

Tabla 9. Registros de egresos o bajas de partes y/o piezas.

\begin{tabular}{ll}
\hline \multicolumn{1}{c}{ Responsable } & \multicolumn{1}{c}{ Descripción } \\
\hline Bodega & $\begin{array}{l}\text { Bodeguero realiza solicitud de baja de activos fijos a la administración } \\
\text { de la empresa. }\end{array}$ \\
Directivos & $\begin{array}{l}\text { Verifica el estado de los activos para confirma si requieren ser dados de } \\
\text { baja. }\end{array}$ \\
\hline
\end{tabular}


Contabilidad

Contabilidad

Contador recibe notificación de administración para que revise registros contables del activo obsoleto.

Directivos

Auxiliar contable verifica fecha de adquisición y departamento responsable.

Administración y el técnico determinan que el bien es inservible para la

Financiero empresa.

Técnico reporta al departamento financiero mediante formulario de baja

Financierode inventario la obsolescencia del bien.

Directivos

Bodeguero

Departamento financiero recibe informe técnico y elabora acta de baja de inventario con la documentación de respaldo del bien obsoleto.

Archivo de documentos de respaldo de baja de inventarios departamento bodega.

\section{Conclusiones.}

- La contabilidad a través del tiempo ha tenido que acoplarse a las nuevas normas para que a nivel mundial los estados financieros tengan un mismo lenguaje y sean de fácil comprensión, contribuyendo a incrementar el nivel de competitividad de los organismos que la emplean como herramienta para el procesamiento de sus transacciones.

- El desconocimiento de ciertos aspectos que señala las NIC 16 y la NIC 36 sobre el manejo contable de propiedad planta y equipo, no permiten aprovechar correctamente los activos, al omitir información en el momento de realizar los cálculos por deterioro y al reconocer esa pérdida, puesto que implica hacer registros de provisiones, por cuanto al existir un valor errado en los costos, las deducciones fiscales se verán afectadas, ya que al ajustarse a los lineamientos de estas normas y una correcta gestión de activos, facilitará a la administración y permitirá realizar una adecuada inversión en propiedad planta y equipo.

- En la fase de diagnóstico se determinó que el Sindicato de Choferes del Guabo, no tiene un control adecuado sobre los bienes que posee y no ha efectuado una valoración de los mismos, convirtiéndose en un problema para esta institución ya que los estados financieros no reflejan su realidad económica-financiera.

- Con el sistema de gestión integral para valuación de activos se ayudará a gestionar de manera correcta la propiedad planta y equipo, logrando la obtención de información 
contable efectiva, así como también la reducción de costos de operatividad, en razón que involucra a todos los departamentos de manera integral, pues al trabajar por separado la información no se compensa correctamente.

- La propuesta del sistema de gestión integral de propiedad, planta y equipo está sustentada en procesos ejecutados en base a políticas para un eficiente control de los bienes, determinando a los responsables o custodios, estableciendo la responsabilidad del buen uso y mantenimiento, con lo cual se pretende lograr que los bienes tengan una mejor operatividad.

\section{Referencias bibliográficas.}

Amendola, L. (2009). Alineacion del Project Management con la estrategia de la organización. Valaencia: Editorial PMN.

Amendola, L. (2011). Libro de gestion integral de activos fisicos. Valencia: Editorial PMN.

British Standars Institution. (BSI). (2008). Pass 55. Gestión de activo parte I. United Kinadom: ISBN:978-0-9563934-0-1.

Coral, L (Ed. septima) (2013). Contabilidad Universitaria. Colombia: Editorial Mc Graw Hill

Fierro, Á. y Fierro F. (Ed. quinta) (2015). Contabilidad general con enfoque NIIF para pymes. Bogotá, Colombia: Editorial Buena Semilla.

García, V. (2017). Contabilidad intermedia primera edición. en México.

Guevara, M. (2015). Propiedad planta y equipo. México: Editorial IMCP.

IASB, C. (2001). Norma Internacional de Contabiliad 36. Deterioro del valor de los activos.

IASB, C. (2005). Norma Internacional de Contabilidad 1. Presentación de Estados Financieros.

Monge, P. (2005). Las normas internacionales de contabilidad. Redalyc, (10), 35-52. Recuperado de http://www.redalyc.org/html/257/25701005/

Maza I., Chavéz C. y Herrera J. (2017). Revalorización de propiedades planta y equipo (PPYE) con fines de financiamiento Universidad y sociedad (3), 184-190. Recuperado en 10 de junio de 2019 de http://scielo.sld.cu/scielo.php?script=sci_arttexr\&pid=s2218$36202017000300029 \& \operatorname{lng}=\mathrm{es} \& \ln \mathrm{l}=\mathrm{es}$. 
Otal, S. (2006). Reconocimiento y valuación de los activos fijos no financieros en las Normas internacionales de información financiera. Saberes, (4), 35-52. Recuperado de http://www.uax.es/publicaciones/archivos/SABEC006_005.pdf

Oliver, H. H. (2010). Contabilidad. Mexico: Editorial.

Zapata, P. (Ed. séptima) (2011). Contabilidad general. Colombia: Gráficas de la Sabana Ltda.

Zapata, P. (2017). Contabilidad general con base en normas internacionales de información financiera octava edicion. Colombia: Gráficas Sara Gallardo.

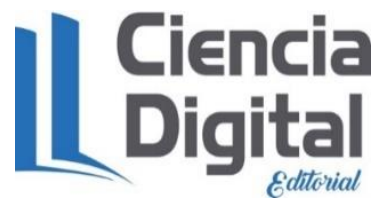




\section{PARA CITAR EL ARTÍCULO INDEXADO.}

Placencia Ordóñez, M., Narváez Zurita, C., Giler Escandón, L., \& Erazo Álvarez, J. (2019). Sistema de gestión integral de propiedad, planta y equipo. Caso: Sindicato de Choferes del cantón El Guabo, Ecuador. Visionario Digital,3(2.1.), 599-624. https://doi.org/10.33262/visionariodigital.v3i2.1.590

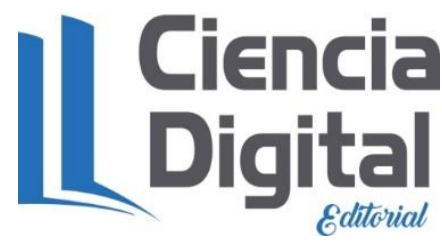

El artículo que se publica es de exclusiva responsabilidad de los autores y no necesariamente reflejan el pensamiento de la Revista Ciencia Digital.

El artículo queda en propiedad de la revista y, por tanto, su publicación parcial y/o total en otro medio tiene que ser autorizado por el director de la Revista Ciencia Digital.
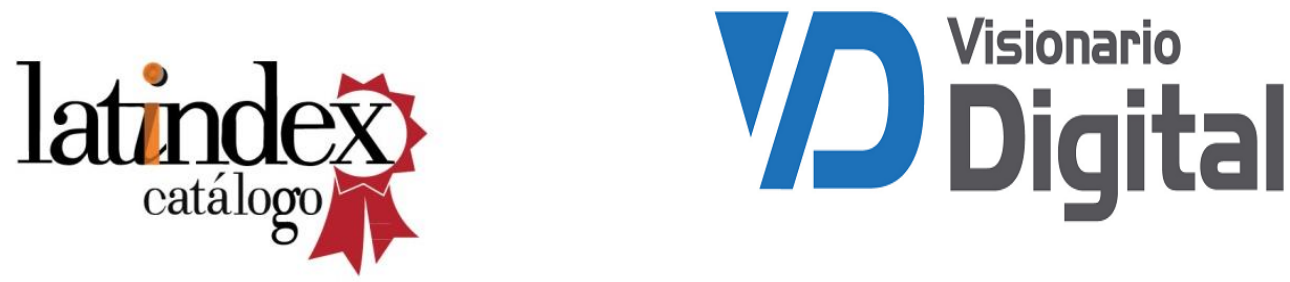